\title{
Numerical Analysis on Steam Exciting Force Caused by Rotor Eccentricity
}

\author{
L. H. Cao, J. X. Wang, P. Li, P. F. Hu, and Y. Li \\ School of Energy and Power Engineering, Northeast Electric Power University, Jilin 132012, China \\ Correspondence should be addressed to J. X. Wang; wjx5749@163.com
}

Received 11 January 2017; Revised 8 May 2017; Accepted 15 May 2017; Published 12 June 2017

Academic Editor: Nuno M. Maia

Copyright (C) 2017 L. H. Cao et al. This is an open access article distributed under the Creative Commons Attribution License, which permits unrestricted use, distribution, and reproduction in any medium, provided the original work is properly cited.

\begin{abstract}
The steam exciting force has been proved to be great threat to the operation safety of steam turbines. The mechanism of steam exciting vibration cannot be profoundly revealed by simply analyzing the steam exciting force, especially in simplified models. Therefore, a full-circle stage of steam turbine with shroud and labyrinth seals was investigated by numerical simulator CFX. The instability of leakage flow and the pressure fluctuation were analyzed on the eccentric condition. The effects of leakage vortexes, the depth-width ratio of seal cavity, and the eccentricity on the steam exciting force were studied. Results show that the leakage flow is nonuniform in the circumferential direction with the change of front teeth vortexes, which causes the steam exciting force. The tangential and radial steam exciting force both increase with the eccentricity increasing. The effects of the depth-width ratio of seal cavity on the two forces are different. In addition, the pressure fluctuation caused by the leakage vortexes on the shroud surfaces is a main factor inducing the steam exciting force. This research provides a theoretical guidance for the operation safety and optimization of steam turbines.
\end{abstract}

\section{Introduction}

A tip leakage loss is caused as part of steam flows through the tip clearance between rotor blade tip and stationary cylinder in a steam turbine. Due to the unsteady leakage flow in the circumferential direction, the pressure fluctuation on the shroud surfaces is nonuniform, which induces the steam exciting force [1].

With the increase of steam turbine capacity, the rotor eccentricity has a great influence on the steam exciting force. The steam exciting force induced by blade tip leakage flow may cause unsteady operation of rotor on certain condition, which seriously affects the unit safety. According to the statistics, there are 158 serious shutdown accidents caused by the shafting vibration, in which $17.1 \%$ of the accidents are caused by the steam exciting force [2]. Therefore, it is significant to study the characteristics of tip leakage flow and the steam exciting force.

Thomas first proposed the theory of steam exciting vibration and deduced the formula to calculate the steam exciting force caused by static eccentricity [3]. But it is quite difficult to accurately select the efficiency factor $\beta$ in applying the formula. The current studies on this problem are mixed and controversial [4-6].

The leakage flow in the seal cavity presents a very complex three-dimensional turbulence which is composed of primary flow and cavity flow [7]. The vortexes in seal cavity present spiral flow due to the rotation of rotor [8]. The unstable leakage flow seriously affects the steam exciting force in the seal. Therefore, it is difficult to accurately calculate the steam exciting force by the formula. Many scholars adopted the experimental method to measure the force [9-11]. But the complex change of the leakage vortexes in the seal cavity which is a major factor leading to the steam exciting force cannot be truly observed from the experiment.

With the rapid development of computational fluid dynamics (CFD), the complex turbulent phenomenon in seal cavity is systematically analyzed. The numerical simulations of the steam exciting force in labyrinth seals were proposed by Mooree et al. [12, 13]. They found that the numerical results were consistent with experimental results. In view of the influence factors of exciting force in labyrinth seals, Ishii et al. pointed out that the labyrinth teeth throttling had more effect on the tangential force component than that on the radial 
TABLE 1: Parameters of blade and seal for calculation.

\begin{tabular}{lc}
\hline Parameter & Value \\
\hline Shroud thickness, $s(\mathrm{~mm})$ & 4 \\
Long teeth height, $\delta_{1}(\mathrm{~mm})$ & 4 \\
Short teeth height, $\delta_{2}(\mathrm{~mm})$ & 2.5 \\
Hub radius, $R_{\text {hub }}(\mathrm{mm})$ & 406.3 \\
Blade height, $l_{b}(\mathrm{~mm})$ & 70.8 \\
Aspect radio, $A_{r}$ & 2.29 \\
Chord, $l(\mathrm{~mm})$ & 30.51 \\
Stagger angle, $\beta_{b}\left(^{\circ}\right)$ & 50.54 \\
\hline
\end{tabular}

one [14]. Besides, the asymmetrical torque and nonuniform pressure also lead to the tangential exciting force, which made the rotor unsteady [15]. However, the above studies have not considered the influence of the structural parameters of labyrinth seals on the steam exciting force.

The three-dimensional unsteady numerical simulation method was adopted by Luan et al. [16, 17] to study the flow field in the blade tip clearance and the spectral characteristics of leakage vortexes in the seal cavity. An eccentric, single labyrinth cavity was investigated on three different inlet swirl conditions and the effect of inlet swirl on the pressure distribution of the shroud surfaces was analyzed [18], while the influence of leakage vortexes on the pressure distribution of the shroud surfaces was not analyzed in the previous research. Leong and Brown [19] pointed out that the circumferential pressure distribution was nearly uniform on concentric condition while it exhibited a nearly cosinoidal distribution on the eccentric condition. However, the pressure distribution on the shroud surfaces in the axial direction was not discussed.

In order to further analyze the factors that induce the steam exciting force, a full-circle high pressure stage of steam turbine with shroud labyrinth seals is studied by the numerical simulator ANSYS CFX 14.5. The effects of leakage vortexes, the depth-width ratio of seal cavity, and the eccentricity are analyzed. Furthermore, the pressure distribution on the shroud surfaces and the steam exciting force caused by nonuniform leakage flow are discussed in depth. It provides a theoretical guidance for the operation safety and optimization of steam turbines.

\section{Model and Grid}

Considering influence of the flow at the inlet and outlet of seal cavity as well as in the flow passage on the steam exciting force, a full-circle high pressure stage of steam turbine with shroud and labyrinth seals is taken as a computation model. The geometric parameters are shown in Table 1 . The numbers of rotor and stator blades are both 100 . The length of stator inlet passage and length of rotor outlet passage are 50\% and $80 \%$ of axial chord, respectively.

Figure 1 shows a high pressure stage of steam turbine in a power plant. The calculated model and seal geometry are shown in Figure 2. In order to generate a high quality computational grid, the main passage domain is divided into several parts. The $\mathrm{HOH}$-type grids are used for the stator

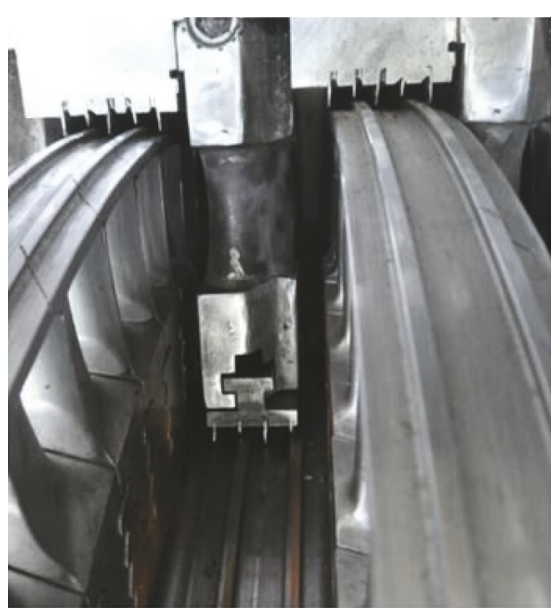

Figure 1: High pressure stage of steam turbine in power plant.

TABLE 2: Relations between leakage flow rate and grids.

\begin{tabular}{lcc}
\hline $\begin{array}{l}\text { Calculation } \\
\text { case }\end{array}$ & $\begin{array}{c}\text { Total grid } \\
\text { number } \\
\text { (million) }\end{array}$ & $\begin{array}{c}\text { Tip leakage flow } \\
\text { rate/(kg/s) }\end{array}$ \\
\hline 1 & 10 & 3.53783 \\
2 & 12 & 3.54342 \\
3 & 14 & 3.55663 \\
4 & 16 & 3.55834 \\
5 & 18 & 3.55938 \\
\hline
\end{tabular}

and rotor blades domain. By software ANSYS ICEM, the structured hexahedral grids are generated in the seal cavity, rotor, and stator flow passage. Blade and seal computation grid are shown in Figure 3.

The rotor eccentricity is shown in Figure 4. The direction of static eccentricity is $Z+$. The direction of tangential steam exciting force is $Y+$. The radial steam exciting force points toward $Z$ - which is opposite to the direction of static eccentricity.

The grid independence was examined by the tip leakage flow rate with the seal teeth number being 5 and the size of tip clearance being $0.75 \mathrm{~mm}$. The relationship between grid number and numerical simulation results on the concentric condition is shown in Table 2. It can be observed that there is no significant effect on the simulation results by increasing the grid number, so the grids of main passage and seal cavity are approximately 8.5 million and 5.5 million, respectively. The total computational grid number is about 14 million.

\section{Numerical Method and Boundary Conditions}

Yakhot and Orszag [20] proposed the RNG $k-\varepsilon$ model. For a stationary state, the unsteady N-S equation is solved by Gauss statistics. The small scale vortexes are eliminated by the frequency spectrum analysis and the influence is merged into the eddy viscosity, so the simulation accuracy of dissipation rate $\varepsilon$ is improved. The difference between RNG $k-\varepsilon$ model 


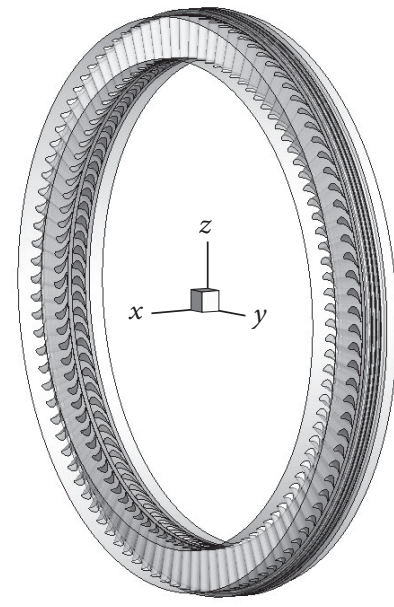

(a) Full-circle model

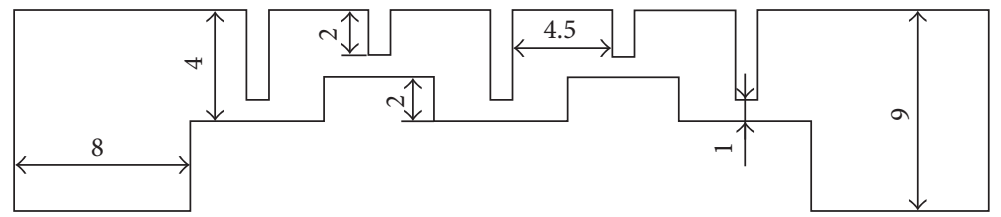

(b) Cross-sectional view of seal cavity/mm

Figure 2: Model and seal geometry.

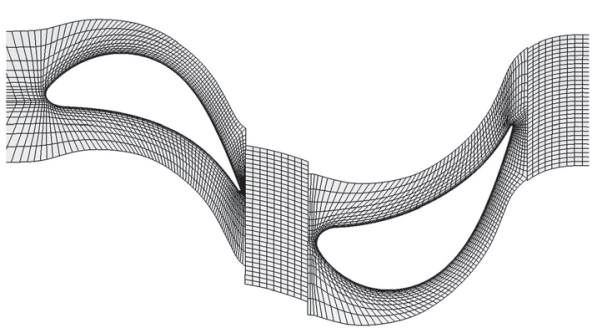

(a)

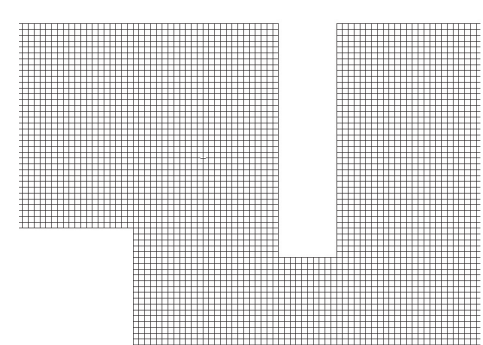

(b)

Figure 3: Blade and seal computation grid.

and standard $k-\varepsilon$ model is the additional nonlinear term $R_{\varepsilon} . R_{\varepsilon}$ plays an important role in improving the calculation accuracy under large strain rate flow and is mentioned in [21].

$$
\begin{aligned}
R_{\varepsilon} & =\frac{C_{\mu} \rho \eta^{3}\left(1-\eta / \eta_{0}\right)}{1+\beta_{0} \eta^{3}} \frac{\varepsilon^{2}}{\kappa}, \\
\eta & =\sqrt{2 S_{i j} S_{j i}} \frac{\kappa}{\varepsilon}
\end{aligned}
$$

where $C_{\mu}, \eta_{0}$, and $\beta_{0}$ are empirical constants, $\rho$ is density, $S_{i j}$ is the average strain tensor, $\varepsilon$ is turbulent dissipation rate, and $\kappa$ is turbulent kinetic energy. The RNG $k-\varepsilon$ model is also validated by literature [22], so the standard RNG $k-\varepsilon$ turbulence model is adopted.

In order to further validate the RNG $k-\varepsilon$ turbulence model, a numerical calculation is carried out for a subsonic stage of steam turbine. The numerical model and boundary conditions are adopted based on experimental data measured by Gatti et al. [22]. Figure 5 shows the comparison between the present results and the experimental results. The tangential velocity $V_{t}$ is taken from the plane at $45 \%$ stator axial chord from the stator trailing edge and is normalized by $V_{t \max }$. As the rotor and stator blade profiles are not exactly the same and the experiment has some errors as well, the maximum relative error of $V_{t} / V_{t \max }$ is 2.3. Therefore, the selection

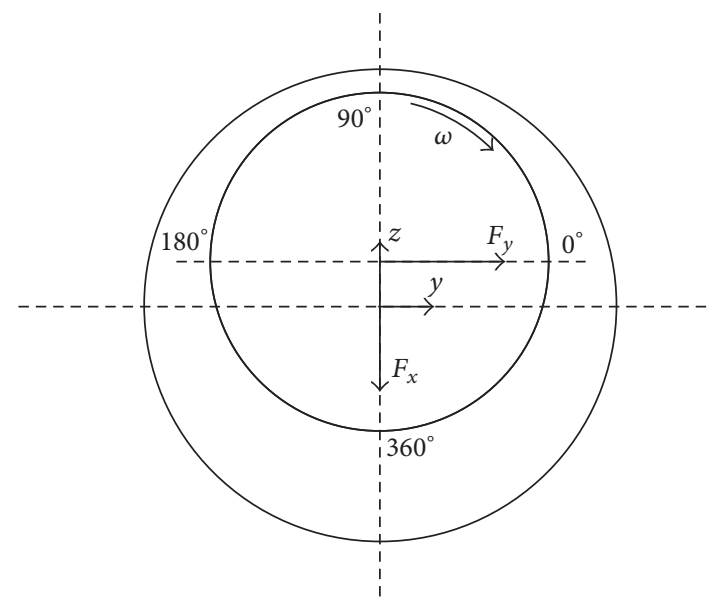

FIGURE 4: The rotor eccentricity in a steam turbine.

of RNG $k-\varepsilon$ turbulence model for numerical computation is reasonable.

An element-based finite volume method is adopted to solve the compressible Reynolds-Averaged Navier-Stokes by the CFD simulator ANSYS CFX 14.5. The continuity equation and the momentum equation are solved simultaneously to ensure the conservation in the time direction. Furthermore, 


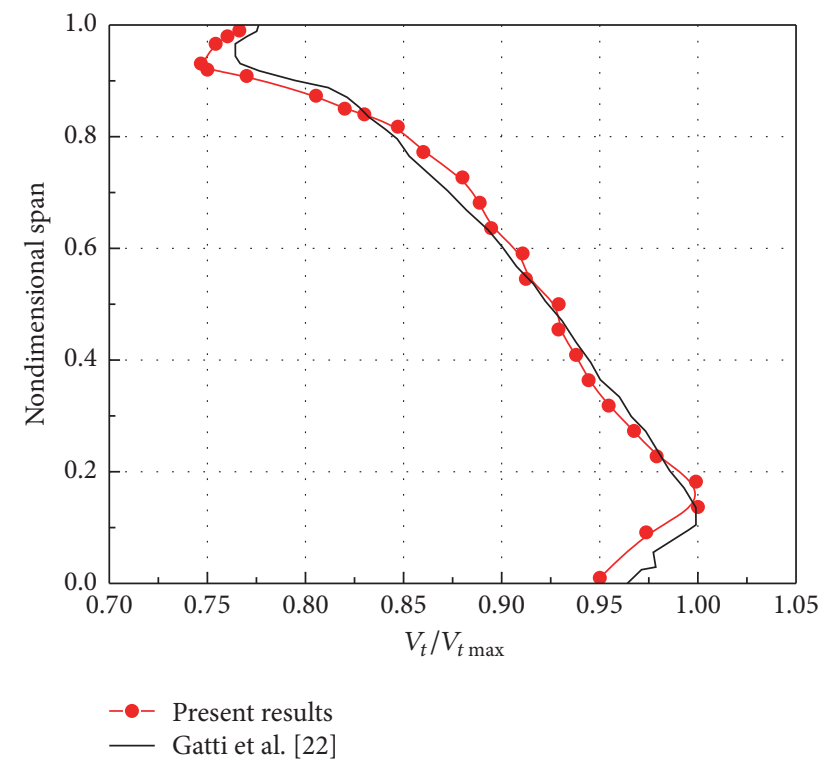

FIGURE 5: $V_{t} / V_{t \max }$ distributions along blade span.

the computation is not constrained by the time step, so the computation by software ANSYS CFX is fast and stable [23].

The difference scheme is a higher order solution. The equations are converged when the residual absolute criteria value is less than $1 e-5$. In order to accurately capture the complex vortexes flow in the blade tip, the method of wall function is adopted. The $y+$ values near the surface of blade and seal are maintained to be about 30 . Superheated steam is adopted as working fluid. Pressure-inlet and pressure-outlet boundary conditions are applied. The inlet total pressure is 11.7 $\mathrm{MPa}$, the total temperature is $756.15 \mathrm{~K}$, and the outlet static pressure is $10.8 \mathrm{MPa}$. All solid walls are assumed as adiabatic and with no slip. The rotation speed is $3000 \mathrm{rpm}$. Frozen rotor technique is applied to deal with the interface.

\section{Results and Discussions}

The efficiency factor $\beta$ of Alford force is used to verify the correctness of numerical simulation results. Based on Alford's force formula in literature [24], $\beta$ can be written in the following generic equation:

$$
\beta=\frac{F_{A} D l_{b}}{\tau e},
$$

where $F_{A}$ is the tangential force generated by rotor eccentricity, N. $D$ and $l_{b}$ are the mean diameter and height of rotor blade, respectively, $\mathrm{m}$. $\tau$ is the torque of rotor, $\mathrm{N} \cdot \mathrm{m} . e$ represents the eccentricity of rotor, $\mathrm{mm}$.

Figure 6 shows the calculation results of the efficiency factor $\beta$ of Alford force. When the seal teeth number is constant, that is, the depth-width ratio of seal cavity is kept constant, $\beta$ increases with the eccentricity increasing. On the other hand, when the eccentricity is kept constant, $\beta$ increases as the seal teeth number increases. The range of $\beta$ is $1.3 \sim 3.3$ which is consistent with the limitation range of $[0.5,8.1]$ for steam turbines [25].

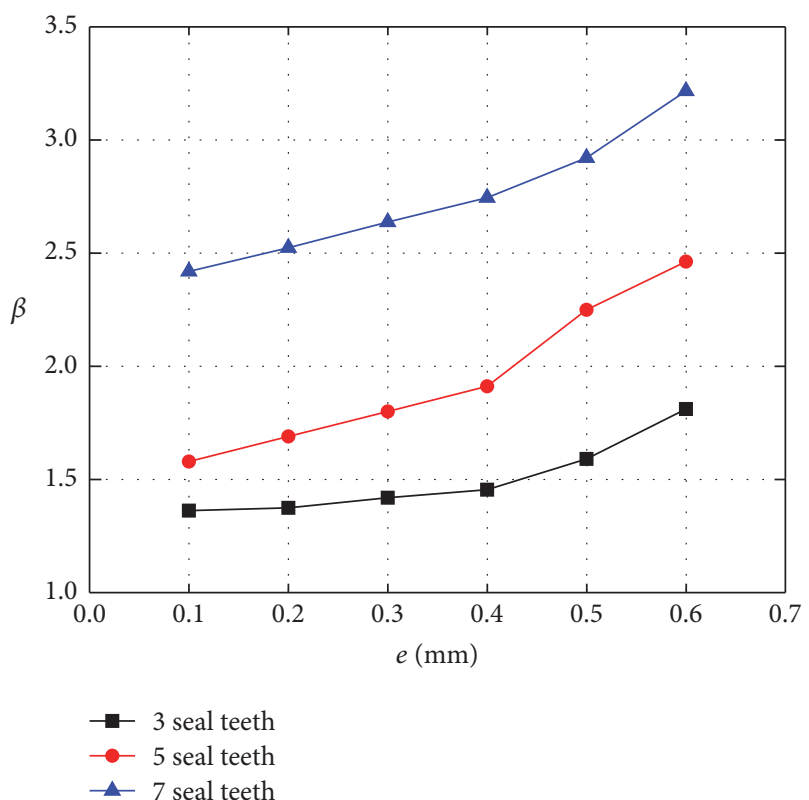

FIgURE 6: Calculation results of the efficiency factor $\beta$ of Alford force.

4.1. Comparative Analysis of Seal Vortex System. There are connections between the steam exciting force and the leakage flow in tip labyrinth seals. Figures 7 and 8 show the leakage flow at $90^{\circ}$ and $270^{\circ}$ on the concentric and eccentric condition, respectively, in seal cavity with 5 teeth. The leakage vortexes in seal cavity are mainly composed of endwall vortexes, front teeth vortexes, and backstep vortexes. It can be seen that the leakage flow has the same characteristics at $90^{\circ}$ and $270^{\circ}$ on the concentric condition, which indicates that the leakage flow is almost the same in circumferential direction, and will not produce unbalanced force.

Comparing Figure 7 with Figure 8, the component of leakage vortexes on the eccentric condition is constant but the size of vortexes is changed. At $90^{\circ}$, the diameter of front teeth vortexes is larger, which weakens the diameter of endwall vortexes nearby. In addition, the diameter of backstep vortexes has little changes. At $270^{\circ}$, the diameter of front teeth vortexes is smaller while other vortexes are basically unchanged. Comparing (a) with (b) in Figure 8, the diameter of leakage vortexes at $90^{\circ}$ in (a) is larger than that in (b), especially for front teeth vortexes. Moreover, the inertia force of leakage flow at $90^{\circ}$ is smaller than that at $270^{\circ}$, which implies that the leakage flow is nonuniform in the circumferential direction because of eccentricity and the circumferential force is nonuniform too. As a result, the steam exciting force is generated in labyrinth seals at the rotor blade tip. Therefore, in the design of seals, it is important to minimize the pressure fluctuation caused by seal teeth under the premise of reducing the leakage flow rate by seal teeth throttling.

4.2. Effects of Eccentricity on Steam Exciting Force. Figure 9 shows the relations between rotor eccentricity and the tangential steam exciting force. The tangential force is influenced 


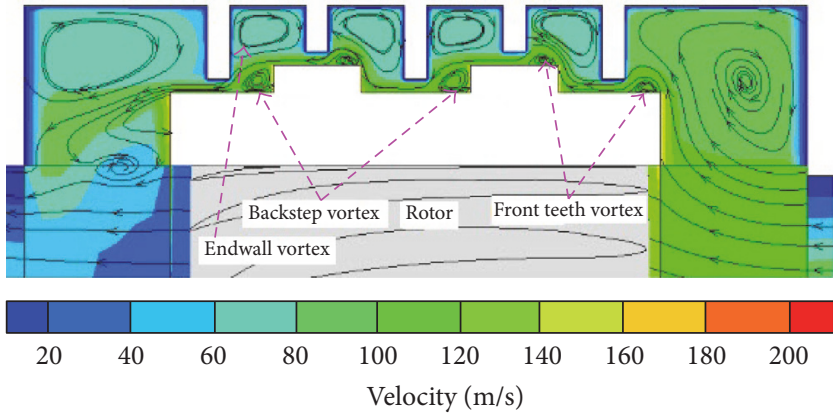

(a) $90^{\circ}$

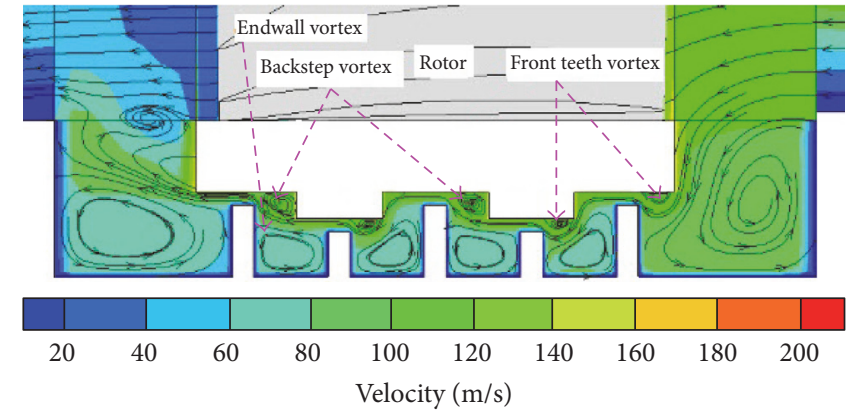

(b) $270^{\circ}$

FIGURE 7: Leakage flow of tip labyrinth seals on concentric condition.

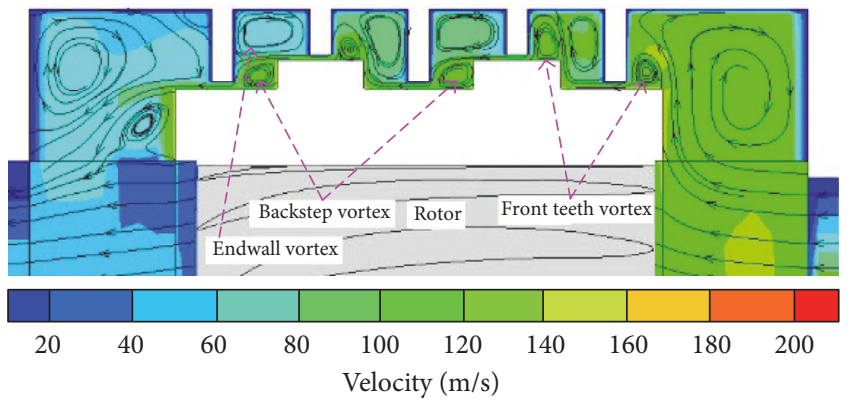

(a) $90^{\circ}$

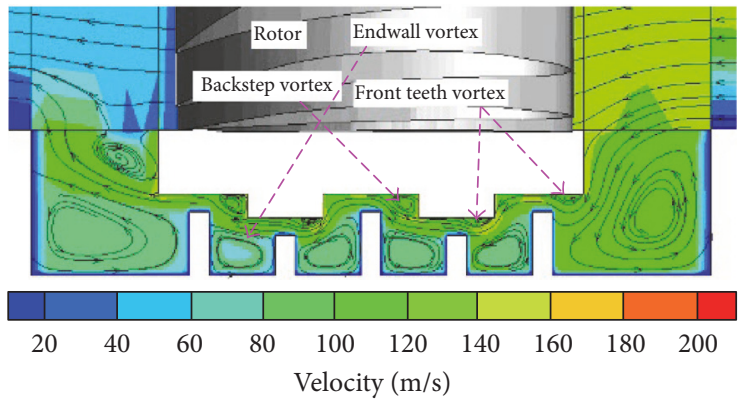

(b) $270^{\circ}$

FIGURE 8: Leakage flow of tip labyrinth seals with $e=0.4 \mathrm{~mm}$.

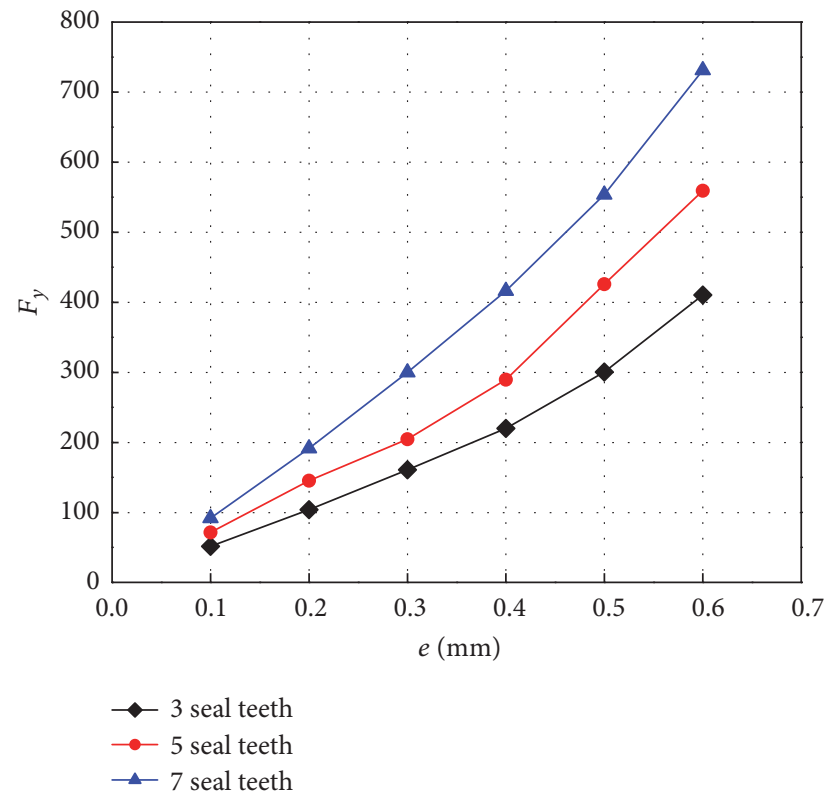

FIGURE 9: Relations between rotor eccentricity and the tangential steam exciting force.

by the velocity, the direction of preswirl of leakage flow, and the asymmetrical circumferential tip clearance. Meanwhile, the influence of leakage flow rate cannot be ignored too.
When eccentricity is certain, the resistance of seal teeth on leakage flow increases and the inertia force decreases with the depth-width ratio of seal cavity increasing. Therefore, the leakage time along the circumferential direction in the tip clearance gets longer, which causes the pressurization and depressurization process of leakage flow in the small and large tip clearance to last longer. As a result, the tangential steam exciting force increases. When the depth-width ratio of seal cavity is certain, the circumferential distribution of tip clearance gets more nonuniform and the change rate of circumferential tip clearance area increases with the eccentricity increasing. So, the pressurized and depressurized pressure gradient near the small and the large tip clearance (at $90^{\circ}$ and $270^{\circ}$ ) are enlarged, respectively, and the pressurized and depressurized effects are enhanced. As a result, the tangential steam exciting force increases.

Figure 10 shows the relations between rotor eccentricity and the radial steam exciting force. The radial steam exciting force is affected by tip clearance, leakage flow rate, radial flow in seal cavity, and axial distance of seal cavity. Based on the analysis of Figure 8, when the seal teeth number is certain, the whirl motion of leakage flow near the small tip clearance $\left(\right.$ at $\left.90^{\circ}\right)$ is more intense and the whirl motion of leakage flow near the large tip clearance (at $270^{\circ}$ ) is less intense on the eccentric condition. There are obvious changes of radial velocity of leakage flow between small and large tip clearance that cause the radial steam exciting force to increase linearly with the increase of eccentricity. When the 


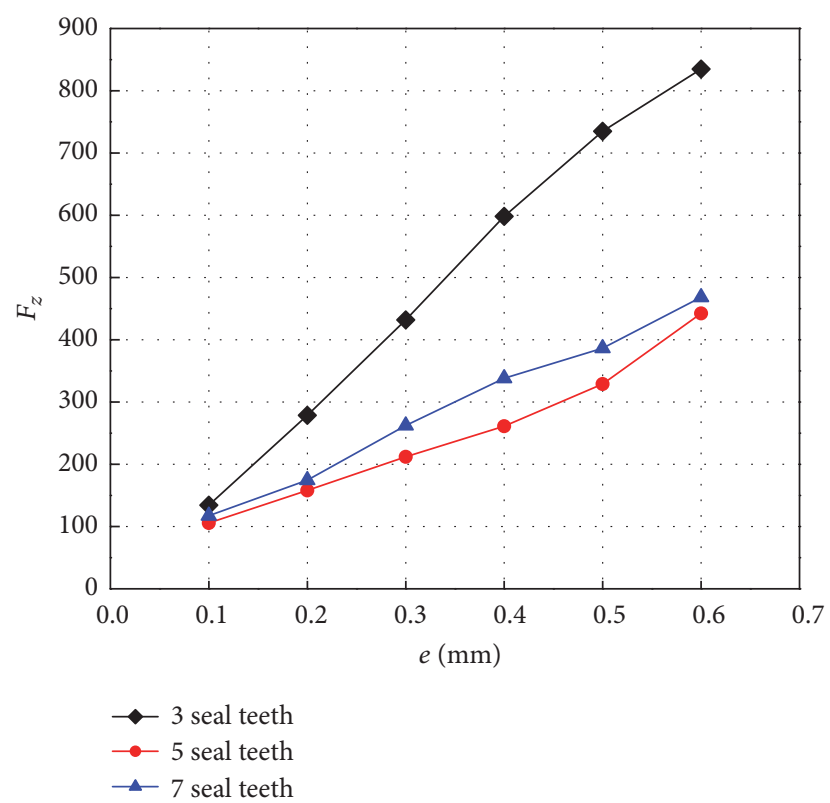

FIGURE 10: Relations between rotor eccentricity and the radial steam exciting force.

eccentricity is constant, the seal cavity with seven teeth has the larger depth-width ratio, so the leakage vortexes change more intensely. Moreover, the seal cavity with seven teeth contains two more cavities than that with five seal teeth, which generates more vortexes and takes more leakage flow time in circumferential direction. The leakage flow rate is the highest with the seal teeth number being three and has a major impact on the radial steam exciting force. Therefore, the gradient of the radial steam exciting force with three seal teeth is the maximum while it is the least with five seal teeth. Consequently, the greater the seal teeth number is, the better the leakage flow rate is reduced. But for the steam exciting force, the more seal teeth number is not the better. So the effects of seal teeth number on the tangential and radial steam exciting force should be considered. The future research can be devoted to determining the optimal number.

4.3. Effects of Eccentricity on Pressure Distribution. The steam exciting force is closely related to the circumferential nonuniform tip leakage flow. Figure 11 shows the two-dimensional pressure contours of the shroud surfaces. The variation of circumferential pressure reflects the nonuniform leakage flow. The direction of leakage flow is from "a" to " $\mathrm{e}$ " in Figure 11.

It can be seen from Figures 11(a)-11(c) that, with the seal teeth number being five, the pressure fluctuation on the surface "a" is more severe. The circumferential leakage flow is nonuniform because of the wake of stator blade. Due to the separation of leakage flow in front of convex platform, there is a significant pressure drop on the interface between "a" and "b," as well as between "c" and "d." On surfaces "a," "b," "c," and " $\mathrm{d}$," the circumferential pressure before seal teeth is divided into the high and low pressure zone at about $180^{\circ}$. The tip clearance at $0^{\circ}-180^{\circ}$ is small due to eccentricity. As a result, the leakage flow is severely compressed, which form a high pressure zone on the shroud surfaces. Thus the high pressure zone is at $0^{\circ}-180^{\circ}$. On the contrary, the low pressure zone is at $180^{\circ}-360^{\circ}$. With the increase of eccentricity, the pressure intensively fluctuates. The pressure difference between the high and low pressure zone increases. The pressure behind seal teeth has little change because it is a pressure expanding process as the leakage flow passes through seal teeth and the leakage flow is nearly parallel to the convex surface.

As shown in Figures 11(a)-11(c), pressure distributes differently on surface "e." The pressure before seal teeth does not change significantly. Under small eccentricity, the high pressure zone is mostly under seal teeth. The circumferential pressure behind seal teeth is divided into the high and low pressure zone at about $180^{\circ}$. The high pressure zone is at $180^{\circ}-360^{\circ}$. The pressure distribution on the surface " $\mathrm{e}$ " is different from other surfaces because the leakage flow in seal cavity outlet has a disturbance on the pressure of the surface "e." The leakage flow rate in large tip clearance at $180^{\circ}-360^{\circ}$ increases with the eccentricity increasing, so the pressure drop is smaller than that in small tip clearance when the leakage flows out of seal cavity. As a result, the pressure is high. As the distribution of pressure on the " $\mathrm{e}$ " surface is opposite to that on the other shroud surfaces, the rotor is subjected to high torque.

The structure of seals with three teeth is relatively simple. When the leakage flows through the seal teeth, the pressure is changed suddenly. And the pressure on the shroud surfaces can be clearly distinguished at $180^{\circ}$ on the same eccentric condition. The high and low pressure distribution before seal teeth show serrated undulation as shown in Figures 11(b), $11(d)$, and 11(e). The pressure changes similarly on surfaces "a" and "b" with seven seal teeth and the axial distance of surface "a" is so short that the leakage flow cannot form front teeth vortexes, which causes little difference between the high and low pressure zone. However, the pressure fluctuation of the subsequent shroud surfaces weakens because of the circumferential interaction of leakage flow which reduces the effect of the stator blade wake. With the increase of seal teeth number, the pressure drop is distributed on each shroud surface, so the pressure distributes evenly on the shroud surfaces with seven seal teeth.

The axial average pressure of the shroud surfaces is shown in Figure 12. It can be seen that the pressure takes on a sinusoidal distribution on the condition that the eccentricity is $0.4 \mathrm{~mm}$ and the seal teeth number is three. The pressure reaches its peak at about $125^{\circ}$ and the pressure is lowest at about $275^{\circ}$. However, the pressure appears to be a parabolic distribution on the other conditions. The pressure peak value increases with the increase of seal teeth number and eccentricity while the pressure valley value decreases with eccentricity when the seal teeth number is constant. As the eccentricity increases, the circumferential pressure difference is larger and the pressure fluctuation is more intense. A similar phenomenon was discussed in literature [21].

In order to verify the reliability of the simulation results in this paper, Figure 13 shows the circumferential pressure 


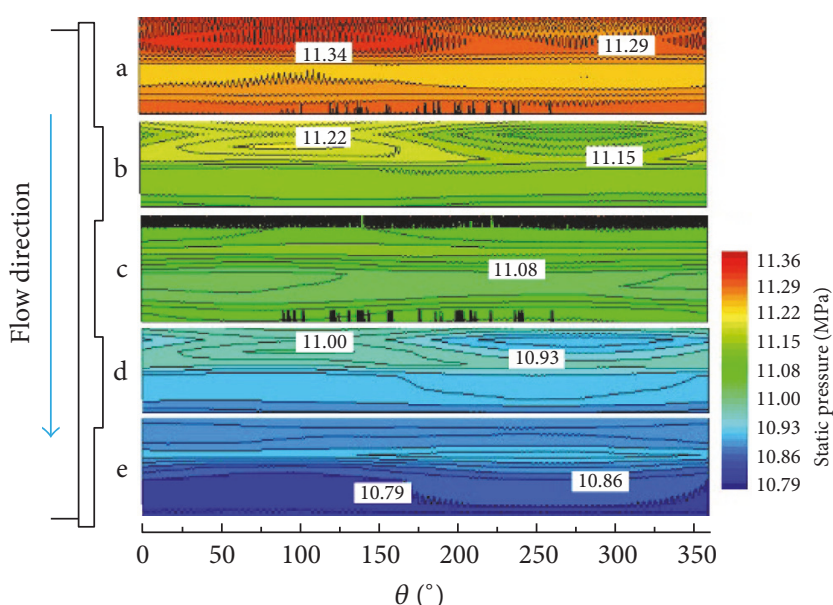

(a) $n=5, e=0.2 \mathrm{~mm}$

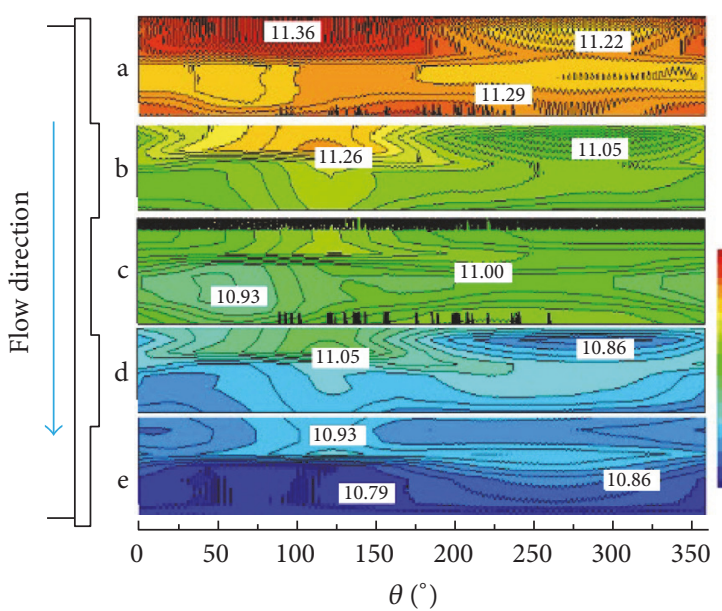

(c) $n=5, e=0.6 \mathrm{~mm}$

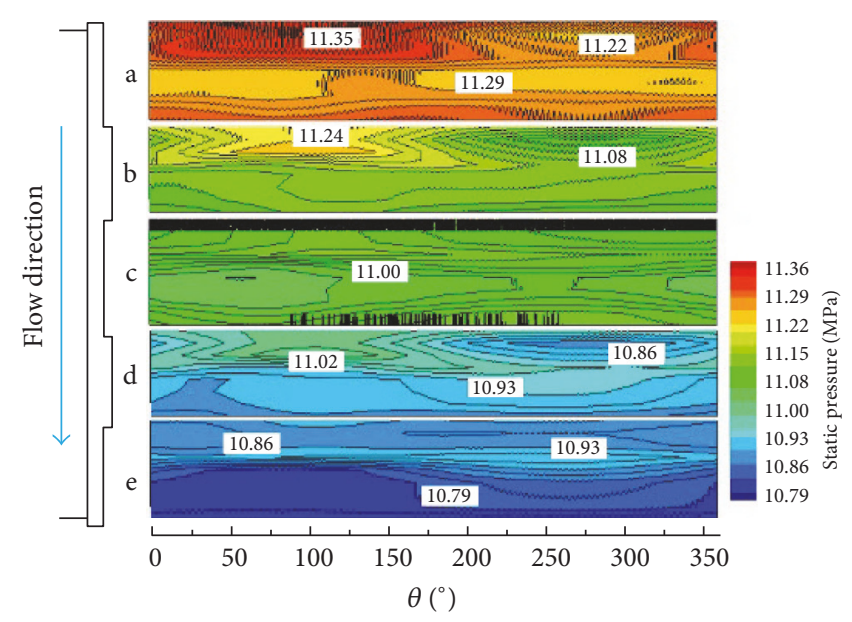

(b) $n=5, e=0.4 \mathrm{~mm}$

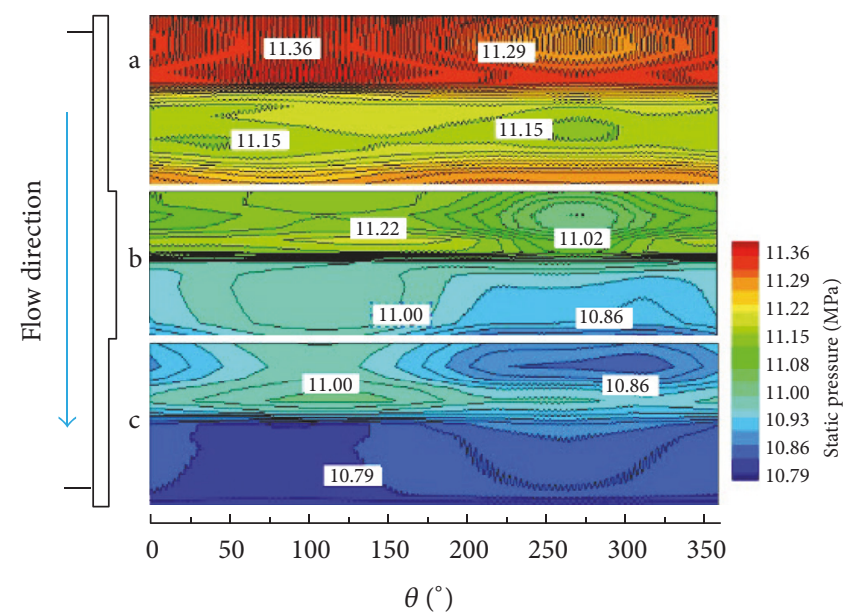

(d) $n=3, e=0.4 \mathrm{~mm}$

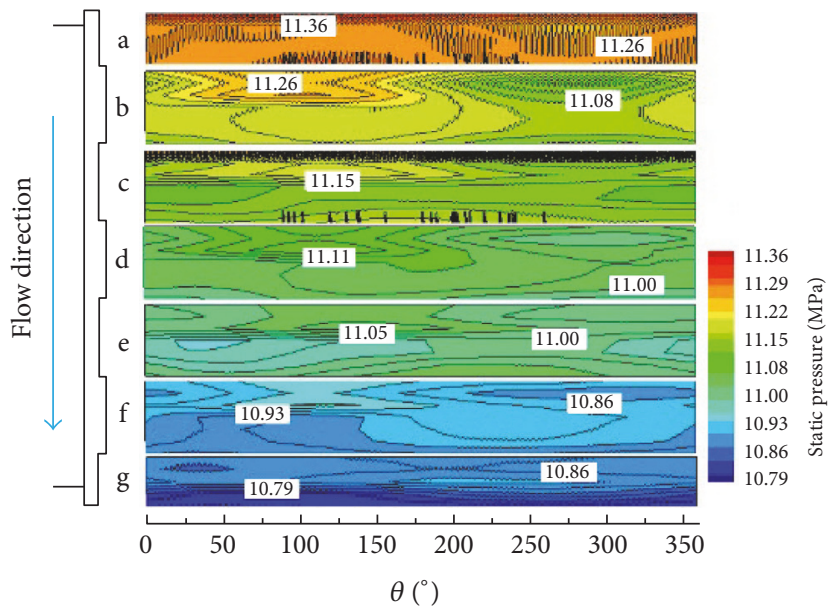

(e) $n=7, e=0.4 \mathrm{~mm}$

FIGURE 11: Two-dimensional pressure contours of the shroud surfaces.

distribution of the last teeth tip. By comparison to the results of Li et al. [26], it is verified that those results are in good agreement. Both the pressure peaks are located at the same area. Although the static pressure values at the inlet and outlet boundary of computational domain in this paper are different from literature [26], those results have the similar change tendency. Therefore, the present results have high reliability and accuracy. 


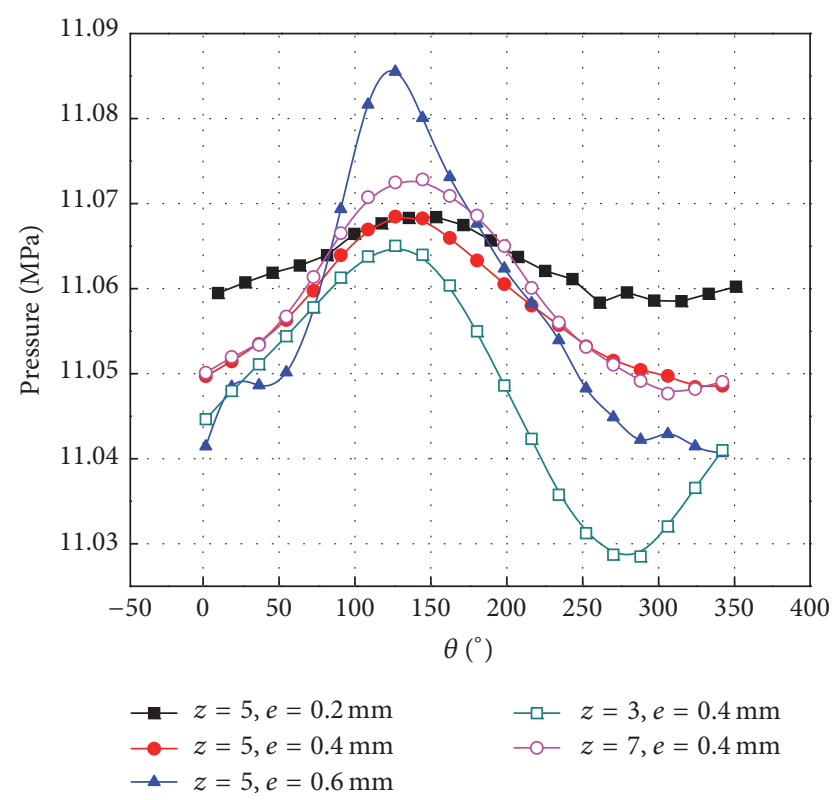

FIGURE 12: Axial average pressure of the shroud surfaces.

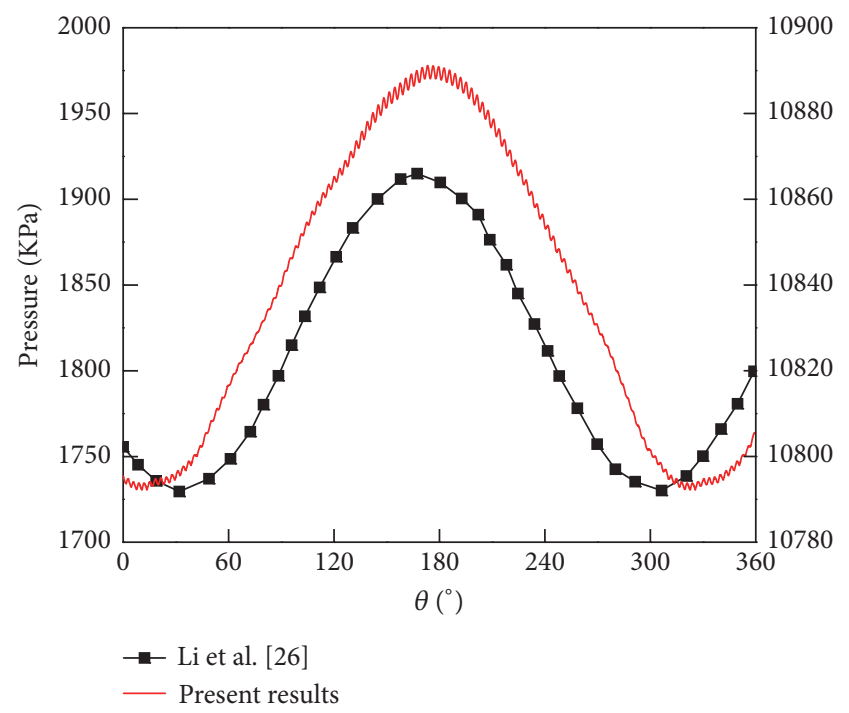

FIgURE 13: Circumferential pressure distribution of the last teeth tip.

\section{Conclusions}

The numerical simulation on the steam exciting force in a full-circle high pressure stage of steam turbine is performed in this paper. The effects of leakage vortexes and depth-width ratio of seal cavity on the steam exciting force on the eccentric condition are studied. The conclusions are summarized as follows.

Compared with the concentric condition, the tip leakage vortexes change a lot on the eccentric condition, and the inertia force of leakage flow at small tip clearance (at $90^{\circ}$ ) is weaker. As a result, the diameter of front teeth vortexes is larger, which causes the pressure on the shroud surfaces to be higher. Furthermore, the boundary between the high and low pressure zone is at about $180^{\circ}$ and the pressure fluctuates more intensely before the seal teeth. In the circumferential direction, the average pressure on the shroud surfaces presents sinusoidal distribution and parabolic distribution. The peak and valley of the average pressure are located at about $125^{\circ}$ and $275^{\circ}$, respectively. With the depth-width ratio and eccentricity increasing, the pressure peak value tends to be larger, while the pressure valley value decreases with the increase of eccentricity. In the axial direction, the pressure on the shroud surfaces shows different fluctuation characteristics near different seal teeth. Particularly, the distribution of the high and low pressure zone near the outlet is opposite to that of the other positions. For the two components of the steam exciting force, the tangential steam exciting force increases with the eccentricity and depth-width ratio. The radial steam exciting force increases with the eccentricity. Therefore, the eccentricity of rotor must be controlled in the operation of steam turbines. At the same time, the structural parameters of blade tip seal should be optimized in the design process.

\section{Conflicts of Interest}

The authors declare that they have no conflicts of interest.

\section{Acknowledgments}

This work was supported by National Natural Science Foundation of China (NSFC) (no. 51576036).

\section{References}

[1] J. Gier, B. Stubert, B. Brouillet, and L. de Vito, "Interaction of shroud leakage flow and main flow in a three-stage LP turbine," Journal of Turbomachinery, vol. 127, no. 4, pp. 649-658, 2005.

[2] J. L. Li, X. H. Guo, C. Yu, and S. H. Huang, "Catastrophe model of steam flow excitation vibration in steam turbine governing stage," vol. 33, pp. 39-46, 2013.

[3] H. J. Thomas, "Unstable oscillations of turbine rotors due to steam leakage in the sealing glands and the buckets," Bulletin Scientifique A J M, vol. 71, no. 11, pp. 223-236, 1958.

[4] J. Colding-Jorgensen, "Prediction of rotor dynamic destabilizing forces in axial flow compressors," Journal of Fluids Engineering, Transactions of the ASME, vol. 114, no. 4, pp. 621625, 1992.

[5] H. S. Kim, M. Cho, and S. J. Song, "Stability analysis of a turbine rotor system with Alford forces," Journal of Sound and Vibration, vol. 260, no. 1, pp. 167-182, 2003.

[6] A. F. Storace, D. C. Wisler, H.-W. Shin et al., "Unsteady flow and whirl-inducing forces in axial-flow compressors: Part I Experiment," Journal of Turbomachinery, vol. 123, no. 3, pp. 433445, 2001.

[7] Z. Lin X, "Analysis of dynamic characteristics of fluid force induced by labyrinth seal," Chinese Journal of Mechanical Engineering, vol. 28, no. 2, pp. 402-408, 2015.

[8] T. Hirano, Z. Guo, and R. G. Kirk, "Application of computational fluid dynamics analysis for rotating machinery - Part II: Labyrinth seal analysis," Journal of Engineering for Gas Turbines and Power, vol. 127, no. 4, pp. 820-826, 2005.

[9] R. Tiwari, S. Manikandan, and S. K. Dwivedy, "A review of the experimental estimation of the rotor dynamic parameters of seals," Shock \& Vibration Digest, vol. 37, no. 4, pp. 261-284, 2005. 
[10] A. O. Pugachev and M. Deckner, "Experimental and theoretical rotordynamic stiffness coefficients for a three-stage brush seal," Mechanical Systems and Signal Processing, vol. 31, pp. 143-154, 2012.

[11] G. Vannini, S. Cioncolini, G. D. Vescovo, and M. Rovini, "Labyrinth seal and pocket damper seal high pressure rotordynamic test data," Journal of Engineering for Gas Turbines and Power, vol. 136, article 022501, no. 2, Article ID 022501, 2014.

[12] J. J. Moore, “Three-dimensional CFD rotordynamic analysis of gas labyrinth seals," Journal of Vibration Acoustics, vol. 125, no. 4, p. 41, 2003.

[13] A. O. Pugachev, U. Kleinhans, and M. Gaszner, "Prediction of rotordynamic coefficients for short labyrinth gas seals using computational fluid dynamics," Journal of Engineering for Gas Turbines and Power, vol. 134, no. 6, Article ID 062501, pp. 1-10, 2012.

[14] E. Ishii, C. Kato, K. Kikuchi, and Y. Ueyama, "Prediction of Rotordynamic Forces in a Labyrinth Seal based on ThreeDimensional Turbulent Flow Computation," JSME International Journal, vol. 40, no. 4, pp. 743-748, 1997.

[15] B. H. Song and S. J. Song, "Lateral forces from single gland rotor labyrinth seals in turbines," Journal of Engineering for Gas Turbines and Power, vol. 126, no. 3, pp. 626-634, 2004.

[16] Z. X. Luan, Y. Li, Y. G. Xue, and L. H. Cao, "Numerical study of the secondary flow loss in steam turbine static cascade," Journal of Northeast China Institute of Electric Power Engineering, vol. 32, no. 2, pp. 43-47, 2012.

[17] L. H. Cao, D. X. Zhang, P. F. Hu, and Y. Li, "Numerical analysis of tip leakage flow in steam turbine rotor cascades," Chinese Journal of Mechanical Engineering, vol. 35, no. 21, pp.5542-5550, 2015.

[18] D. L. Rhode, S. J. Hensel, and M. J. Guidry, "Three-dimensional computations of rotordynamic force distributions in a labyrinth seal," Tribology Transactions, vol. 36, no. 3, pp. 461-469, 1993.

[19] Y. M. M. S. Leong and R. D. Brown, "Circumferential pressure distributions in a model labyrinth seal," 1982.

[20] V. Yakhot and S. A. Orszag, "Renormalization group analysis of turbulence. I. Basic theory," Journal of Scientific Computing, vol. 1, no. 1, pp. 3-51, 1986.

[21] Y. H. Xie, J. B. Lan, and T. Fan, "Investigation of three dimensional viscous unsteady flow and excitation force of turbomachinery stage," vol. 28, pp. 78-84, 2008.

[22] G. Gatti, P. Gaetani, B. Paradiso et al., "An Experimental Study of the Aerodynamic Forcing Function in a 1.5 Steam Turbine Stage," Journal of Engineering for Gas Turbines and Power, vol. 139, article 052503, no. 5, 2017.

[23] S. Djouimaa, L. Messaoudi, and P. W. Giel, “Transonic turbine blade loading calculations using different turbulence models effects of reflecting and non-reflecting boundary conditions," Applied Thermal Engineering, vol. 27, no. 4, pp. 779-787, 2007.

[24] X. J. Ding, G. Wang, S. H. Huang, and C. G. Zheng, "Calculation method of efficiency factor in Alford's force," J. Huazhong Univ. of Sci. Tech. (Nature Science Edition), vol. 31, no. 3, pp. 66-68, 2003.

[25] S. Subramanian, A. S. Sekhar, and B. V. S. S. S. Prasad, "Rotordynamic characteristics of rotating labyrinth gas turbine seal with centrifugal growth," Tribology International, vol. 97, pp. 349359, 2016.

[26] X. Li, J. Yang, and W. Xu, "Research and comparison on the leakage and fluid force between the axial and the radial labyrinth seal," Journal of Mechanical Science and Technology, vol. 29, no. 11, pp. 4611-4620, 2015. 


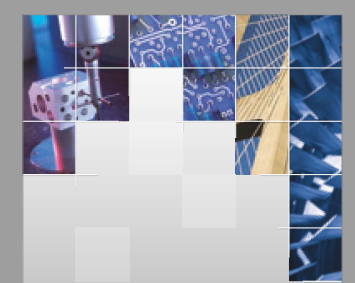

\section{Enfincering}
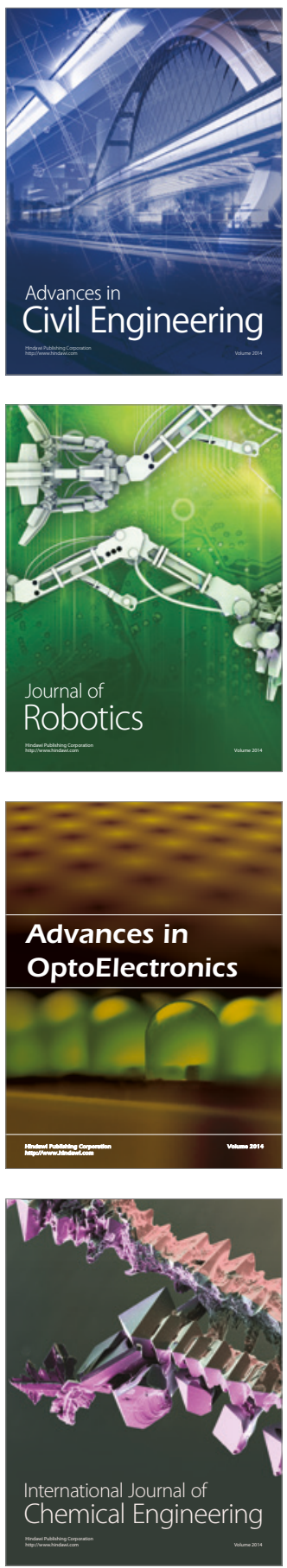

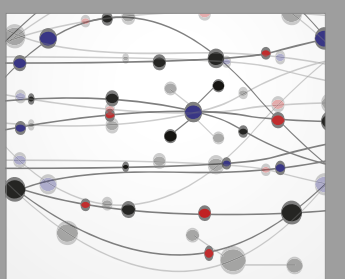

The Scientific World Journal

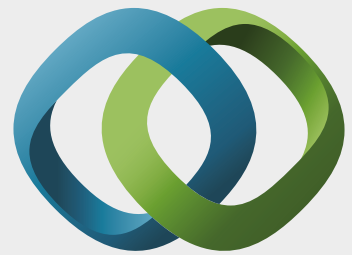

\section{Hindawi}

Submit your manuscripts at

https://www.hindawi.com
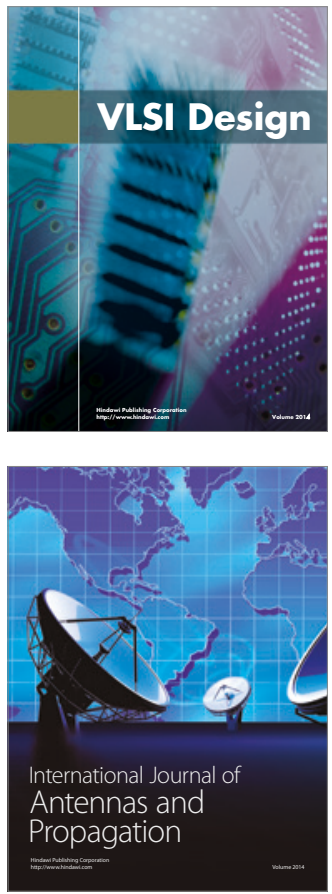

\section{Rotating}

Machinery
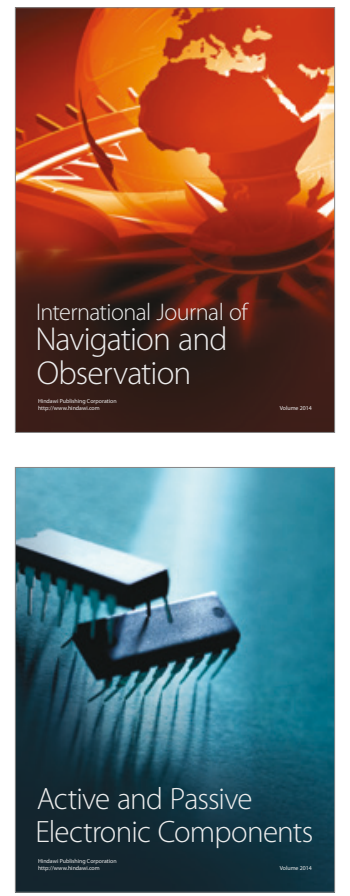
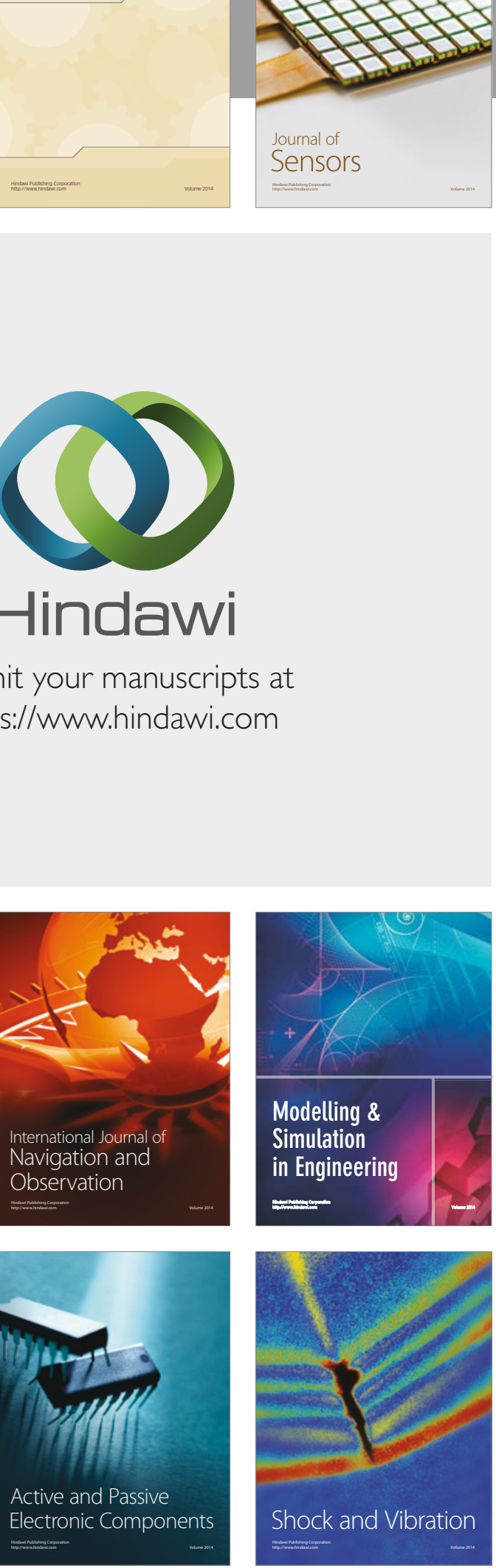
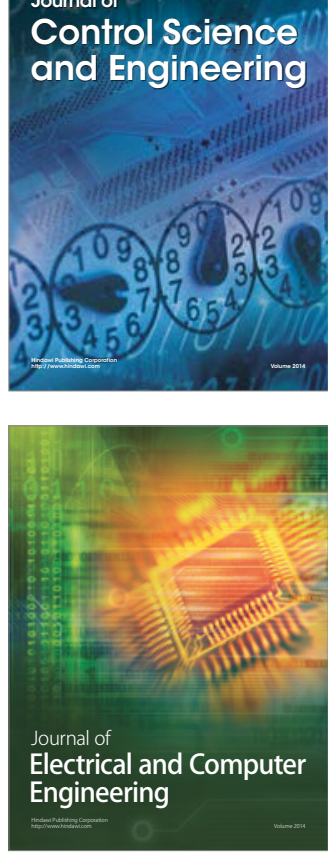

Distributed

Journal of

Control Science

and Engineering
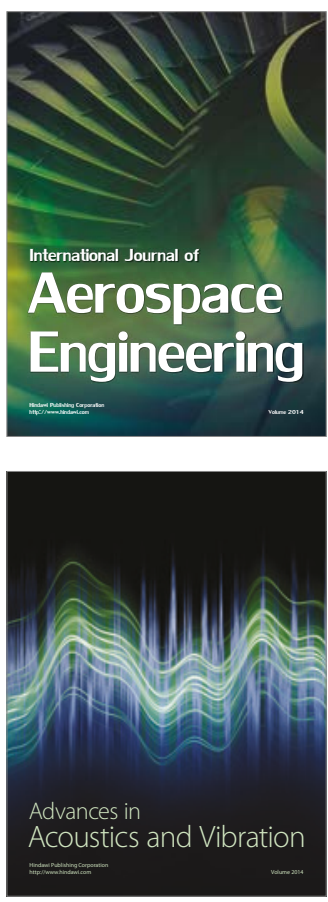

Sensor Networks 